\title{
Nationwide study of the treatment of mycotic abdominal aortic aneurysms comparing open and endovascular repair in The Netherlands
}

Citation for published version (APA):

Dang, Q., van Eps, R. G. S., Wever, J. J., Veger, H. T. C., Dutch Society of Vascular Surgery, Steering Committee of the Dutch Surgical Aneurysm Audit, Dutch Society of Vascular Surgery, \& Teijink, J. (2020). Nationwide study of the treatment of mycotic abdominal aortic aneurysms comparing open and endovascular repair in The Netherlands. Journal of Vascular Surgery, 72(2), 531-540. https://doi.org/10.1016/j.jvs.2019.09.060

Document status and date:

Published: 01/08/2020

DOI:

10.1016/j.jvs.2019.09.060

Document Version:

Publisher's PDF, also known as Version of record

\section{Document license:}

Taverne

Please check the document version of this publication:

- A submitted manuscript is the version of the article upon submission and before peer-review. There can be important differences between the submitted version and the official published version of record.

People interested in the research are advised to contact the author for the final version of the publication, or visit the DOI to the publisher's website.

- The final author version and the galley proof are versions of the publication after peer review.

- The final published version features the final layout of the paper including the volume, issue and page numbers.

Link to publication

\footnotetext{
General rights rights.

- You may freely distribute the URL identifying the publication in the public portal. please follow below link for the End User Agreement:

www.umlib.nl/taverne-license

Take down policy

If you believe that this document breaches copyright please contact us at:

repository@maastrichtuniversity.nl

providing details and we will investigate your claim.
}

Copyright and moral rights for the publications made accessible in the public portal are retained by the authors and/or other copyright owners and it is a condition of accessing publications that users recognise and abide by the legal requirements associated with these

- Users may download and print one copy of any publication from the public portal for the purpose of private study or research.

- You may not further distribute the material or use it for any profit-making activity or commercial gain

If the publication is distributed under the terms of Article $25 \mathrm{fa}$ of the Dutch Copyright Act, indicated by the "Taverne" license above, 


\title{
Nationwide study of the treatment of mycotic abdominal aortic aneurysms comparing open and endovascular repair in The Netherlands
}

\author{
Quan Dang, MD, Randolph G. Statius van Eps, MD, PhD, Jan J. Wever, MD, PhD, and Hugo T. C. Veger, MD, \\ in collaboration with the Dutch Society of Vascular Surgery, the Steering Committee of the Dutch Surgical \\ Aneurysm Audit, and the Dutch Institute for Clinical Auditing, ${ }^{*}$ The Hague, The Netherlands
}

\begin{abstract}
Objective: Mycotic aneurysms of the abdominal aorta (MAAA) can be treated by open repair (OR) or endovascular aneurysm repair (EVAR). This nationwide study provides an overview of the situation of MAAA treatment in The Netherlands in 2016.

Methods: A retrospective cohort study was conducted with all centers that registered aortic abdominal aneurysms in the Dutch Surgical Aneurysm Audit in 2016. Questionnaires on 1-year outcomes were sent to all centers that treated patients with MAAA. The primary aim was to determine 30-day and 1-year mortality and morbidity of OR- and EVAR-treated patients. Morbidity was determined by the need for reoperations and the number of readmissions to the hospital.

Results: Twenty-six MAAA were detected in the Dutch Surgical Aneurysm Audit database of 2016, resulting in an incidence of $0.7 \%$ of all registered abdominal aortic aneurysms. The 30-day mortality for OR and EVAR treated patients was 1 in 13 and $O$ in 13, respectively. Major and minor reinterventions within 30 days were needed for two (one OR and one EVAR) and two (one OR and one EVAR) patients, respectively. Two patients (15.4\%) in the OR group and one patient (7.7\%) in the EVAR group were readmitted to hospital within 30 days. In total, 1-year outcomes of 23 patients were available. In the OR group, one patient (9.1\%) died in the first postoperative year. There was one major reintervention (removal of endoprosthesis and spiralvein reconstruction) in the EVAR group. Two patients (18.2\%) treated with OR and two (16.7\%) treated with EVAR required a minor reintervention. In both groups, four patients (OR, 36.4\%; EVAR, 33.3\%) were readmitted to hospital within 1 year postoperatively.

Conclusions: Both OR- and EVAR-treated patients show acceptable clinical outcomes after 30 days and at the 1-year follow-up. Depending on the clinical course of the patient, EVAR may be considered in the management of this disease. (J Vasc Surg 2020;72:531-40.)
\end{abstract}

Keywords: Mycotic; Infectious; Abdominal aneurysm; Endovascular aneurysm repair; Clinical audit

The term mycotic aortic aneurysm was first coined to describe an infected aorta as a secondary complication of endocarditis. 'It seems to be a misnomer nowadays, because infections of the aorta are rarely caused by fungal micro-organisms. The term infected aneurysm, which encompasses infections of preexisting aneurysms and primary artery infections resulting in an aneurysm, is considered to be more comprehensive than mycotic aortic aneurysm. ${ }^{2}$ In Europe, incidence rates vary between $0.6 \%$ and $2.0 \%$ of all aortic aneurysms. However, the incidence goes up to $13 \%$ in East Asia owing to the high prevalence of Salmonella infections, which are often responsible for infected aneurysms..$^{3-5}$ Compared with atherosclerotic aneurysms, mycotic aneurysms have a worse prognosis, because they have a tendency to grow rapidly and a relatively high risk of rupture. Moreover, patients with mycotic aortic aneurysm often already have severe comorbidities before admission., ${ }^{6,7}$

Diagnosing a mycotic aortic aneurysm can be challenging owing to the lack of standardized diagnostic criteria. Blood cultures may contribute to the diagnosis, but a negative blood culture cannot rule out the diagnosis because blood cultures are found to be negative in $25 \%$ to $50 \%$ of all patients with these aneurysms. ${ }^{6-8}$
From the Department of Vascular Surgery, Haga Teaching Hospital. *The Dutch Society of Vascular Surgery, the Steering Committee of the Dutch Surgical Aneurysm Audit, and the Dutch Institute for Clinical Auditing collaborators are listed in the Appendix at the end of this article. Author conflict of interest: none.

Additional material for this article may be found online at www.jvascsurg.org. Correspondence: Quan Dang, MD, Department of Vascular Surgery, Haga Heart and Vascular Center, Haga Teaching Hospital, Els Borst-Eilersplein 275, 2455 AA The Hague, The Netherlands (e-mail: michaelqdang@yahoo.com).

\footnotetext{
The editors and reviewers of this article have no relevant financial relationships to disclose per the JVS policy that requires reviewers to decline review of any manuscript for which they may have a conflict of interest. 0741-5214

Copyright $\odot 2019$ by the Society for Vascular Surgery. Published by Elsevier Inc https://doi.org/10.1016/j.jvs.2019.09.060
} 
Whether a positive blood culture is required for the diagnosis remains a point of discussion. ${ }^{9-12}$ In the absence of specific computed tomography (CT) findings and negative blood cultures, a mycotic aortic aneurysm may still exist, but may also easily be mistaken for an inflammatory aneurysm. Inflammatory aneurysms usually have an autoimmune cause, are sterile, and require a different treatment approach. ${ }^{13}$

The treatment of a mycotic aneurysms of the abdominal aorta (MAAA) involves surgery and administration of antibiotics, but the optimal treatment is uncertain. Open repair (OR) was long regarded as the gold standard, but at the end of the previous millennium, endovascular aneurysm repair (EVAR) was introduced for MAAA as possible curative treatment. ${ }^{14}$ Over the years, it has shown to be an acceptable and durable treatment option ${ }^{15,16}$ although it can still be regarded with skepticism by not resecting the infected area and placing foreign material inside the MAAA.

Owing to the rarity of the disease, it is difficult to perform large-scale studies with sufficient statistical power. Most of the previous studies were from a single center and had a heterogeneous study population. The scarcity in reliable data leads to local differences in the approach and treatment of MAAA.

This study describes the experience of MAAA treatment in The Netherlands, based on the Dutch Surgical Aneurysm Audit (DSAA) data from 2016. The primary aim is to assess the 30-day and 1-year mortality and morbidity of patients with MAAA treated with OR or EVAR. In addition this study evaluated the incidence of MAAA, the rationale for choosing OR or EVAR and the duration of postoperative antibiotic treatment.

\section{METHODS}

Patient and data collection. A retrospective cohort study was conducted with all 57 centers in The Netherlands that registered patients in the DSAA in 2016. The DSAA is a quality registration of the Dutch Institute of Clinical Auditing. This nationwide registration for aneurysms aims to improve the quality of aneurysm surgery. ${ }^{17}$ The initial DSAA registration consists of the following parameters: patient characteristics and comorbidities, aneurysm characteristics, laboratory results, surgical intervention details, complications, and postoperative course (ie, treatment outcomes through 30 days postoperative). Postoperative morbidity was determined by the need for reoperations and the number of readmissions to the hospital.

Our inclusion process consisted of two steps, that is, (1) selecting potential patients who could possibly have a MAAA from the DSAA database and (2) eligibility assessment by a vascular surgeon of each participating center. For the first step, all 57 hospitals that treat abdominal aortic aneurysms (AAA) were asked to participate and

\section{ARTICLE HIGHLIGHTS}

Type of Research: Multicenter, retrospective cohort study of the Dutch Surgical Aneurysm Audit

Key Findings: In 26 patients with mycotic abdominal aortic aneurysms, the 30-day mortality was 1 in 13 (7.7\%) for open repair (OR) and 0 in $13(0.0 \%)$ for endovascular aneurysm repair (EVAR). After 1 year, one additional OR-treated patient died. Five patients required reintervention in the follow-up period ( 3 EVAR, 2 OR).

Take Home Message: Acceptable clinical outcomes were seen after 1 year follow-up in OR- and EVARtreated patients with mycotic abdominal aortic aneurysm. Depending on the clinical course of the patient, EVAR may be considered in the management of this disease.

share their data of potential patients with MAAA (ie, AAA registered with an infectious, [auto-]inflammatory or unknown origin) registered in the DSAA database between January 1, 2016, and December 31, 2016. Access was only granted to anonymized patient data in the registry after obtaining permission from the treating hospitals. Owing to privacy regulations, review of patient charts for eligibility assessment and additional data collection could only be done by (a vascular surgeon of) the participating center itself. Central data monitoring by the researchers was not possible; data fidelity was confirmed by every participating center.

To classify an AAA as mycotic, diagnostic criteria that were most commonly used in the literature and daily practice, were mostly adopted (ie, clinical presentation [pain, fever $\geq 38^{\circ} \mathrm{C}$, sepsis, and/or concomitant infection], laboratory tests [elevation of inflammatory markers like C-reactive protein and white blood cells, and/or positive cultures], and/or specific findings on CT scan or magnetic resonance imaging [rapid expansion of the AAA, saccular morphology, multilobular aneurysms/eccentric aneurysms, periaortic gas, and/or periaortic soft tissue mass]). Besides having been classified as MAAA by (a vascular surgeon of) the participating center, all included patients in our study must have received antibiotic treatment other than the perioperative prophylaxis. In The Netherlands, where the policy on use of antibiotics is quite restrictive for the purpose of preventing antibiotic resistance, it is likely that patients received antibiotic treatment before or after the procedure only when a MAAA was highly suspected. Exclusion criteria were (1) secondarily infected aneurysms (eg, revisions owing to infected grafts), (2) inflammatory AAA without antibiotic treatment other than perioperative antibiotic administration, and (3) infected aneurysms located elsewhere. 
A self-made questionnaire (see the Appendix, online only) was used to prospectively acquire additional information regarding the preoperative, perioperative, and postoperative course. More specifically, the following information was acquired: method of MAAA diagnosis, cultured pathogens and antibiotic treatment, rationale for choosing OR or EVAR, type of OR and postoperative morbidity from 30 days to 1 year.

Data management. Castor EDC (Amsterdam, The Netherlands) was used as data management software. Questionnaires were also made and sent with this software. All registry data were anonymized and could not be linked to individual patients by the researchers. Because these registrations were done in the context of quality improvement, additional consent from the patients was not necessary.

Ethics. The study was approved by the local ethical committee of the HACA hospital (METCZWH18-018). The study conforms to the STROBE guideline for cohort studies. $^{18}$

Data analysis. Data analysis was performed using SPSS 25 (IBM; Chicago, III). Descriptive statistics were used to describe the mortality and morbidity of the OR and EVAR approach. Nominal and ordinal variables were reported as frequencies and percentages. Pearson's $\chi^{2}$ or Fisher's exact test was used to compare categorical data, as appropriate. Continuous variables were reported as means and standard deviations and were compared using the Mann-Whitney U-test. A $P$ value of less than .05 was considered as significant.

\section{RESULTS}

A total of 3740 patients with an AAA were registered in the DSAA of 2016 (Fig 1). Only nine centers did not provide permission within the study period. A total of 47 aneurysms with an infectious or inflammatory pathogenesis were identified, treated in 26 hospitals. Twenty-one cases were excluded after sending the questionnaires, not meeting the inclusion criteria for MAAA. Eight patients with MAAA were not classified as infectious in the DSAA database but appeared to have antibiotic treatment or positive cultures. With 26 patients included in the analyses, the observed incidence of MAAA in 2016 was $0.7 \%$ among the registered AAA. For the 1-year analysis, long-term data for three patients could not be retrieved by the hospitals and were regarded as lost to follow-up. Therefore, 23 patients were included in the 1-year analysis, 11 patients in the OR group and 12 in the EVAR group.

Clinical characteristics. The baseline characteristics of the 26 included patients are displayed in Table I. The mean age of the OR and EVAR group were 70.7 years and 67.1 years, respectively. Cardiac history was unremarkable in three and six patients of the $O R$ and EVAR group, respectively. One patient in the OR group had malignancy at time of MAAA diagnosis. The mean size of all included MAAA were $50.8 \mathrm{~mm}$ and $54.8 \mathrm{~mm}$ for the OR and EVAR groups, respectively; most MAAA were located infrarenal $(84.6 \%$ in the OR group and $92.3 \%$ in the EVAR group).

In the diagnostic process (Table II), a CT angiogram was used in $61.5 \%$ of the OR and $76.9 \%$ of the EVAR group. Preoperative positive cultures were seen in almost half of the cases of the two treatment groups (OR, 38.5\%; EVAR, 46.2\%). Of 26 cases, 16 (61.5\%) had positive cultures when adding the perioperative and postoperative results of the cultures. In three cases, the clinical presentation was also determinative for MAAA diagnosis.

Blood cultures showed a large variety of microorganisms. An infection with Coxiella burnetti, which was determined by serology, occurred in two patients. Infection with Salmonella species (typhymurium and group D), Staphylococcus species (hominis, capitis, and epidermidis) and Streptococcus species (agalactiae, sanguis, and pneumoniae) were seen in four, three, and three patients, respectively. All aneurysms without positive cultures were treated with postoperative antibiotics, although one of these cases was also treated with preoperative antibiotics.

Urgent surgery within 72 hours after presentation was performed in 18 patients (7 OR, 11 EVAR). Within 2 hours after clinical presentation, four patients were treated with $\mathrm{OR}$ and two patients were treated with EVAR. Symptomatic aneurysm was the reason for an urgent (ie, within 72 hours) operation in $92.3 \%$ and $63.6 \%$ of the EVAR and OR group, respectively. Approximately one-third (36.4\%) of all OR patients underwent an acute OR owing to rupture of the aneurysm.

Only $23.1 \%$ of all patients treated with OR were anatomically eligible for EVAR; the reasons for not choosing the other treatment modality were patient comorbidity (23.1\%), condition of the patient (15.4\%), and preference of the operating team (7.7\%). In six EVAR treated cases (46.2\%), OR was not chosen because of the preference of the operating team for endovascular treatment. In seven cases $(53.8 \%)$ the reason for not choosing OR was the poor condition or the many comorbidities of the patient.

Treatment characteristics. Table III shows the surgical details of the included patients. The most often performed type of OR was an in situ reconstruction (61.5\%). Two EVAR patients received a spiralvein reconstruction at a later moment; one of these patients was treated with EVAR as bridge to spiralvein reconstruction, the other was unintended.

OR-treated patients were hospitalized for a mean of 20.6 days, of which a mean of 11.8 days spent in the intensive care unit (ICU). For the EVAR treated patients, these 


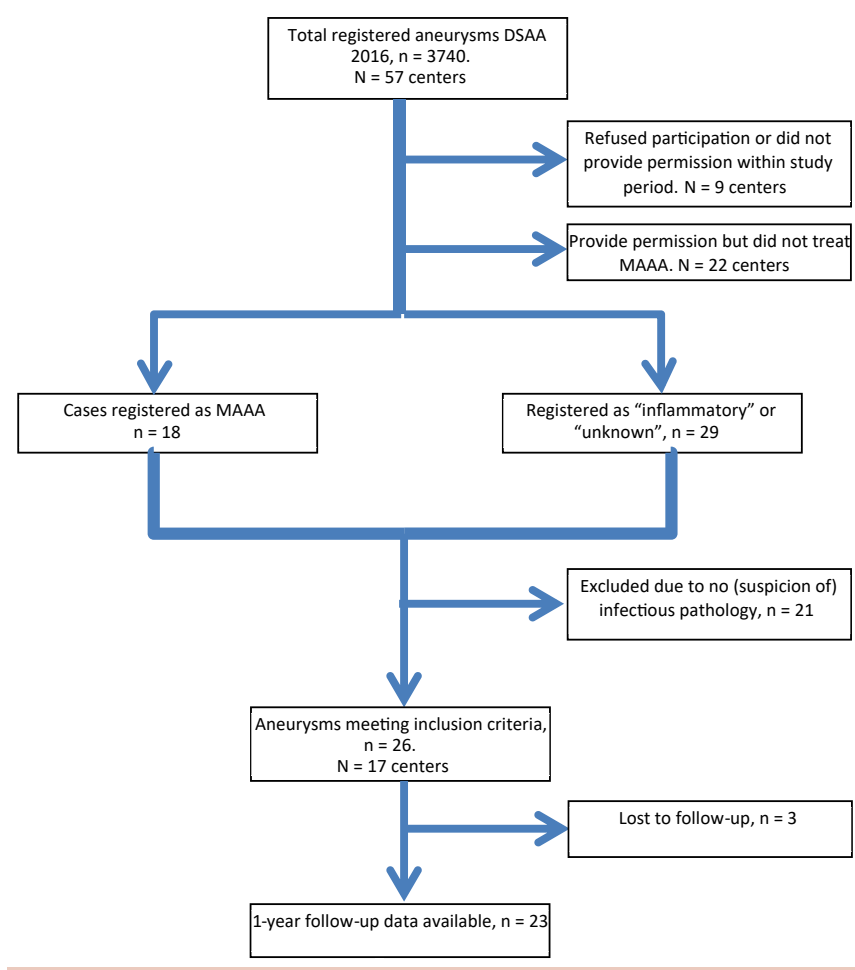

Fig 1. Inclusion criteria. DSAA, Dutch Surgical Aneurysm Audit; MAAA, mycotic aneurysm of the abdominal aorta.

durations were on average 17.1 days (total) and 0.46 days, respectively.

All patients received postoperative antibiotic treatment during hospitalization (Fig 2). The duration of the antibiotic treatment after discharge varied between 6 weeks and ongoing. The postoperative use of antibiotics was unknown in five patients (two lost to followup and three no information available). Only one patient had a persistent ongoing infection with Coxiella burnetti. This patient and the other two patients with ongoing antibiotic treatment (hydroxychloroquine, amoxicillin, clindamycin respectively) were all treated with EVAR.

Postoperative mortality. One patient of the OR group died within 30 days after the procedure for an unknown reason (Table IV). In the EVAR group, no deaths were observed in the 30-day postoperative time frame. In the postoperative course between 30 days and 1 year, only one patient treated with OR died (9.1\%).

Postoperative morbidity. A major reintervention within 30 days was required in one patient $(7.7 \%)$ treated with OR and one patient (7.7\%) treated with EVAR. Minor reinterventions were needed for one patient (7.7\%) in the OR group and one (7.7\%) in the EVAR group. In total, three patients (two OR, one EVAR) were readmitted to the hospital within 30 days.
Four patients in each group were readmitted to the hospital in the period through 1 year postoperative. In total, four patients (two OR, two EVAR) received a minor reintervention. The minor reinterventions in the $O R$ group (16.7\%) were a puncture of abdominal abscess and percutaneous transluminal angioplasty owing to occlusion or stenosis of the extra-anatomic bypass. In the EVAR group the minor reinterventions (18.2\%) were CT puncture of an infected para-aortic hematoma, and type III endoleak treated by additional endograft placement. One major reintervention (8.3\%) was needed for an EVAR-treated patient (removal of the endoprothesis and spiralvein reconstruction owing to persisting infection with Capnocytophaga canimorsus).

\section{DISCUSSION}

This nationwide study gives a comprehensive overview of the situation regarding MAAA treatment in the period of 1 year in The Netherlands. Among all registered AAA, the incidence of MAAA in this study was $0.7 \%$, which was in concordance with previous reported incidences of MAAA in Western Europe (0.6\%-2.0\%). Of the 13 OR-treated patients, one died within 30 days and one within 1 year. No mortality was observed in the EVAR group. In total, four and five reinterventions were needed in OR- and EVARtreated patients, respectively. This is the first study to provide such overview of MAAA treatment in current vascular surgical practice.

In the present study, mortality rates are lower than those reported in previous studies. ${ }^{6,19-27}$ This difference could be explained by (technical) innovations in MAAA care in recent decades. Previous studies have mainly included patients treated in a period when MAAA care was not as established as it was in 2016. Moreover, the difference in mortality rates may also be due to the fact that patients from previous studies had more comorbidities than those from our cohort. For example, in a study by Sörelius et $a{ }^{19},{ }^{19}$ a main cause of death was cancer among the selected patients, whereas in our study only a few patients with MAAA suffered from cancer. Unfortunately, our database could only analyze cardiac, pulmonary, and malignancy status; owing to the main purpose of quality registration, the DSAA database lacked detail on other comorbidities. Other studies had a longer followup time than the 1 year in our study. The study from Sörelius et $\mathrm{al}^{19}$ also showed that especially the first year postoperatively is important for mortality and morbidity. However, infection related death still occurs in the period of 1 to 5 years of follow-up.

The present study highlights the complexity and heterogeneity in MAAA diagnosis and management. First, the lack of standardized diagnostic criteria for MAAA 22 is also appreciable in our study. To decrease the likeliness of excluding misregistered MAAA cases, all aneurysms which were registered as inflammatory or unknown 
Volume 72, Number 2

Table I. Demographic and clinical characteristics of the patients included in the analyses $(N=26)$

\begin{tabular}{|c|c|c|c|}
\hline & OR $(n=13)$ & $\operatorname{EVAR}(n=13)$ & $P$ value \\
\hline Age, years & $70.7 \pm 7.3$ & $67.1 \pm 10.5$ & .362 \\
\hline Male sex & $11(84.6)$ & $9(69.2)$ & .64 \\
\hline Cardiac status preoperative & & & .29 \\
\hline No cardiac history & $5(38.5)$ & $6(46.2)$ & \\
\hline Use of hypertension medication & $3(23.1)$ & $3(23.1)$ & \\
\hline Peripheral edema & $3(23.1)$ & $\mathrm{O}(0.0)$ & \\
\hline Missing & $2(15.4)$ & $4(30.8)$ & \\
\hline Malignancy & & & .54 \\
\hline No & $10(76.9)$ & $12(92.3)$ & \\
\hline Actual malignancy & $1(7.7)$ & $\mathrm{O}(0.0)$ & \\
\hline Curative $>5$ years & $1(7.7)$ & $1(7.7)$ & \\
\hline Curative $<5$ years & $1(7.7)$ & $\mathrm{O}(0.0)$ & \\
\hline Pulmonary status preoperative & & & .41 \\
\hline No dyspnea & $8(61.5)$ & $11(84.6)$ & \\
\hline Dyspnea of effort & $3(23.1)$ & $1(7.7)$ & \\
\hline Unknown & $2(15.4)$ & $1(7.7)$ & \\
\hline \multicolumn{4}{|l|}{ Preoperative measurements } \\
\hline Systolic pressure & $117.1 \pm 27.7$ & $138.7 \pm 27.6$ & .18 \\
\hline Unknown & $1(7.7)$ & $\mathrm{O}(0.0)$ & \\
\hline Heart rate & $94.8 \pm 19.2$ & $91.9 \pm 31.1$ & .31 \\
\hline Unknown & $2(15.4)$ & $\mathrm{O}(0.0)$ & \\
\hline Creatinine & $123.8 \pm 71.7$ & $85.9 \pm 25.2$ & .32 \\
\hline Unknown & $1(7.7)$ & $\mathrm{O}(0.0)$ & \\
\hline GCS preoperative & & & .18 \\
\hline 15 & $10(76.9)$ & $13(100.0)$ & \\
\hline $12-14$ & $1(7.7)$ & $\mathrm{O}(0.0)$ & \\
\hline$<9$ & $2(15.4)$ & $\mathrm{O}(0.0)$ & \\
\hline \multicolumn{4}{|l|}{ Aneurysm characteristics } \\
\hline Diameter, millimeters & $50.8 \pm 13.4$ & $54.8 \pm 10.1$ & .47 \\
\hline Registered as infectious & $10(76.9)$ & $8(61.5)$ & .67 \\
\hline Location of the aneurysm & & & .99 \\
\hline Suprarenal & $2(15.4)$ & $1(7.7)$ & \\
\hline Infrarenal & $11(84.6)$ & $12(92.3)$ & \\
\hline
\end{tabular}

etiology were also assessed. Indeed, eight patients with MAAA (30.8\%) were not classified as infectious in the DSAA database. An important limitation is that no consensus has been reached yet on whether a positive blood or aortic tissue culture is necessary for the diagnosis. In our study, preoperative positive blood cultures were obtained in fewer than one-half of the cases. If adding the positive perioperative and postoperative obtained cultures, the amount of positive cultures rises up to more than $60 \%$ of the patients, which is in concordance with previous studies. ${ }^{6,23,24}$ However, even if other findings are strongly suggestive of a MAAA, blood culture results can still be negative. Besides, with EVAR treatment the possibility of tissue culture is impeded. A large proportion of the patients can also have negative cultures owing to difficulties in growing these organisms after administration of broad-spectrum antibiotics. ${ }^{10,17-19}$

Second, the clinical management of patients with MAAA is quite heterogeneous in The Netherlands. For example, surveillance protocols were not harmonized between different centers and several choices in the clinical pathway of patients with MAAA (eg, size threshold for MAAA repair, prosthesis type) were at the discretion of the treating physician. With regard to therapeutic decision making, our questionnaire showed that the rationale for choosing an OR depended mainly on anatomical characteristics of the aneurysm, making it technically impossible to perform an EVAR (seven cases). However 
Table II. Pretreatment phase $(\mathrm{N}=26)$

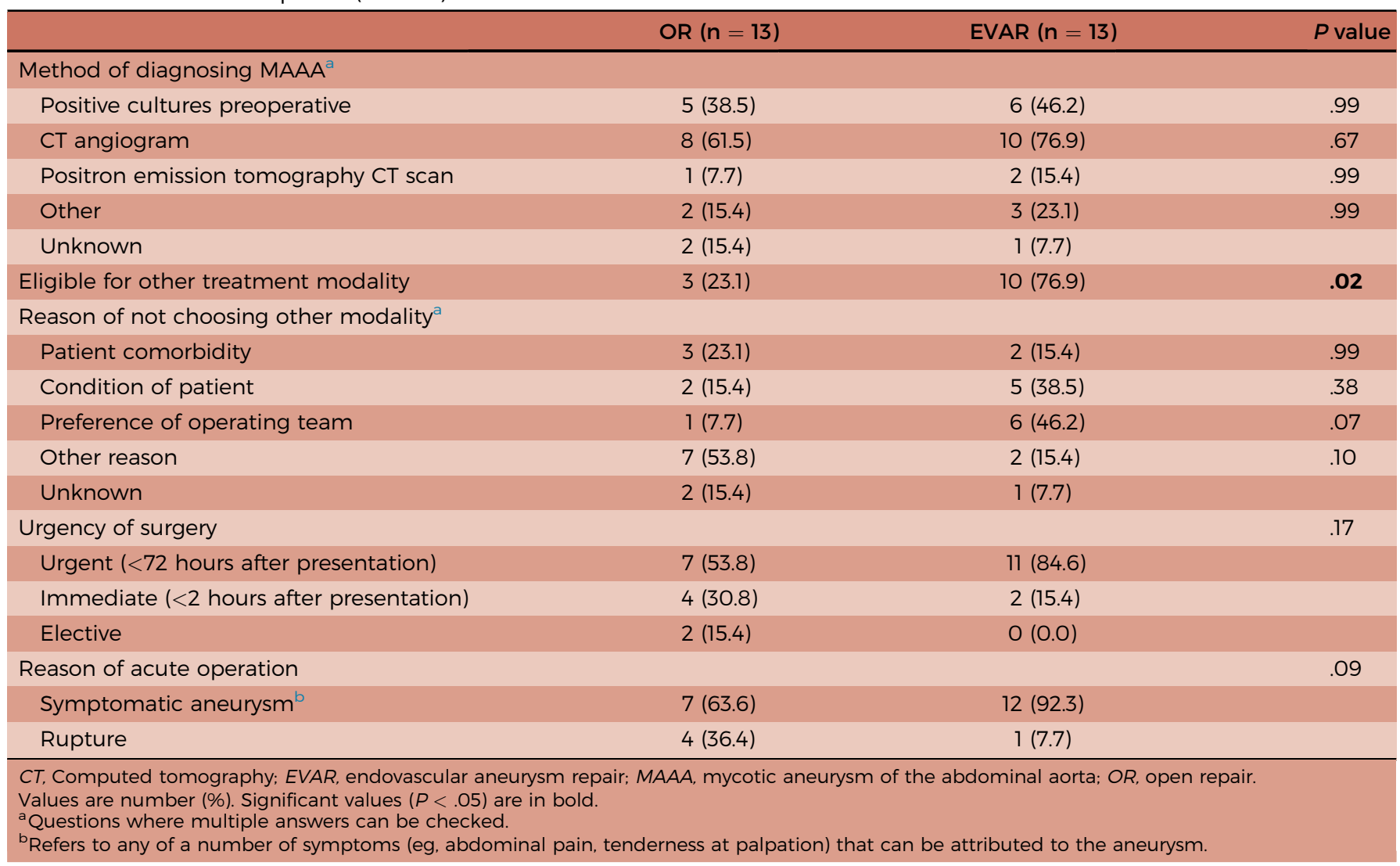

no standardized anatomic criteria for feasibility assessment of repair by EVAR were used. Besides anatomic aneurysm characteristics, it is important to determine which patient will benefit from which treatment modality. Our questionnaire mentioned possible relevant factors as patient condition or comorbidities, but exact details regarding the decision making process are lacking.

Given these inconsistencies, it is important to standardize the diagnostic process and decision making in patients with MAAA. Regarding the diagnostic criteria, we suggest that a positive blood or aortic tissue culture may be helpful in the diagnosis of MAAA, but should not be a requirement. It may be suggested that OR treated patients should be in good condition, given the extended postoperative course at the ICU in our study. Unfortunately, the obtained data are inadequate to correct for comorbidities and general condition of the patients. However, because an OR is an invasive surgical procedure, it is likely that the postoperative course of OR-treated patients will also be demanding. Therefore, EVAR may specifically be chosen in patients unfit for OR with a morphologically suitable MAAA to control the rupture of the aneurysm and the ongoing sepsis. Initial EVAR treatment can be regarded as a definitive solution if the infection is under control. If the infection persists, EVAR could serve as a bridge to another definitive treatment option, that is, resection of the infected aneurysm by additional OR. As EVAR have increasingly successfully been adopted for MAAA treatment in the past 15 years, we expect that in the future, more patients with MAAA may be treated in this way.

The optimal antibiotic regime for MAAA also remains challenging. Early antibiotic treatment can impede the confirmation of the diagnosis, but it is suggested that preoperative administration of antibiotics to control the infection before surgical intervention gives the best results. However, selection bias may have influenced these results. ${ }^{10,19,25,26}$ Nevertheless, to enable (considering) EVAR treatment, it may be important to start with preoperative, preferably broad-spectrum antibiotic treatment because a major drawback of treating patients with MAAA by EVAR is that antibiotic treatment cannot be adapted to the micro-organism (obtained from tissue culture) causing the infection. Postoperatively, we observed a large variation ( 6 weeks to lifelong treatment) in antibiotic treatment duration. Previous studies have also reported a considerable variation in duration of antibiotic treatment, ranging from 4 weeks to lifelong antibiotics in some cases. ${ }^{19-21}$ In our cohort, EVAR-treated patients specifically tend to use postoperative antibiotics for a longer period, probably owing to the placement of foreign material in an infected area, which requires monitoring of the infection postoperatively and administration of intravenous antibiotic treatment if necessary. This factor can also 
Table III. Surgical characteristics $(N=26)$

\begin{tabular}{|c|c|c|c|}
\hline & $\mathrm{OR}(n=13)$ & EVAR $(n=13)$ & $P$ value \\
\hline Performed modality of open repair & & & - \\
\hline Spiralvein reconstruction & $0(0.0)$ & $2(16.7)$ & \\
\hline Extra-anatomic bypass & $1(7.7)$ & $0(0.0)$ & \\
\hline Biograft & $2(15.4)$ & $\mathrm{O}(0.0)$ & \\
\hline In situ reconstruction with synthetic prosthesis & $8(61.5)$ & $0(0.0)$ & \\
\hline Unknown & $2(15.4)$ & $0(0.0)$ & \\
\hline Perioperative complications & & & .59 \\
\hline No & $11(84.6)$ & $12(92.3)$ & \\
\hline Type I endoleak & $\mathrm{O}(0.0)$ & $1(7.7)$ & \\
\hline Intestine damage & $1(7.7)$ & $0(0.0)$ & \\
\hline Other & $1(7.7)$ & $0(0.0)$ & \\
\hline Perioperative blood loss, $\mathrm{mL}$ & & & $<.01$ \\
\hline$<100$ & $\mathrm{O}(0.0)$ & $7(53.8)$ & \\
\hline $101-500$ & $3(23.1)$ & $3(23.1)$ & \\
\hline$\geq 501$ & $10(76.9)$ & $0(0.0)$ & \\
\hline Missing & $0(0.0)$ & $3(23.1)$ & \\
\hline Days on ICU & $11.8 \pm 23.9$ & $0.46 \pm 1.1$ & $<.01$ \\
\hline Missing & $1(7.7)$ & $\mathrm{O}(0.0)$ & \\
\hline Days of hospitalization & $20.6 \pm 17.4$ & $17.1 \pm 27.4$ & .13 \\
\hline Missing & $4(30.8)$ & $0(0.0)$ & \\
\hline
\end{tabular}

\section{Duration of antibiotics after surgery}

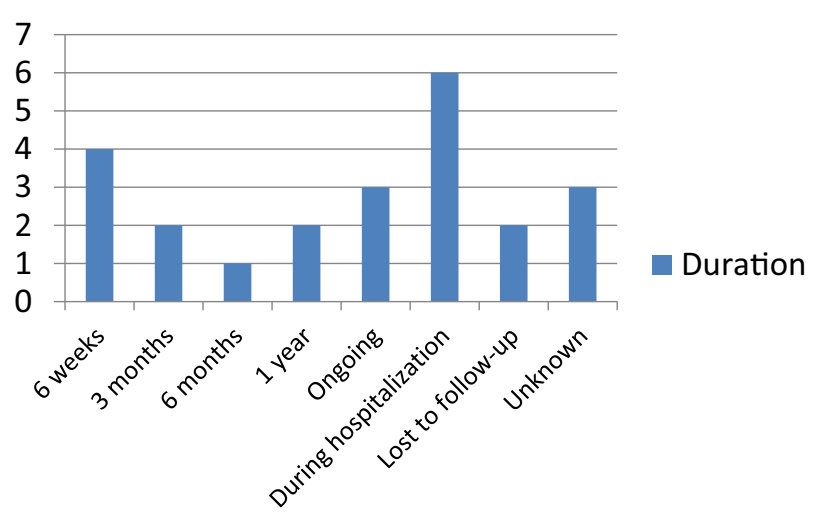

Fig 2. Duration of antibiotic treatment postoperative.

explain the comparable hospitalization durations of EVAR-treated patients compared to OR-treated patients (17.1 days vs 20.6 days, respectively).

Last, similar to AAA care, which is not centralized in The Netherlands, patients with MAAA were treated in hospitals throughout the whole country, including in the relatively small peripheral ones. Moreover, the volume of patients with MAAA per hospital was quite low (mostly one or two cases per hospital). The discussion of centralization of AAA treatment indicating that a higher annual volume improves outcome, ${ }^{27-31}$ may be even more pronounced in the more complex situation of MAAA cases. Although mortality rates were already relatively low in The Netherlands, there remains room for further improvement with regard to postoperative morbidity (eg, shortening the hospitalization duration [for EVAR patients] and length of ICU stay [for OR patients], or decreasing the number of reinterventions and readmissions postoperatively). Our data showed that centralization is feasible in terms of transport: in most cases, surgical treatment was initiated within 72 hours or planned electively, indicating that there would have been enough time to transport the patient to another center.

Strengths and limitations. The main strength of our study is that we obtained permission of almost all centers that could have treated patients with MAAA to share their data, thereby enabling us to provide a comprehensive overview of the Dutch MAAA situation in 2016. Because reasons for not participating were mainly logistical and privacy-related issues (and thus were not associated with study outcomes), bias owing to selective inclusion was quite unlikely.

A limitation of the study is the retrospective design. We used data from the DSAA registry, but because this quality registration mainly serves for auditing purposes, (detailed) information on patients with MAAA was limited. As a 
Table IV. Thirty-day and 1-year outcomes

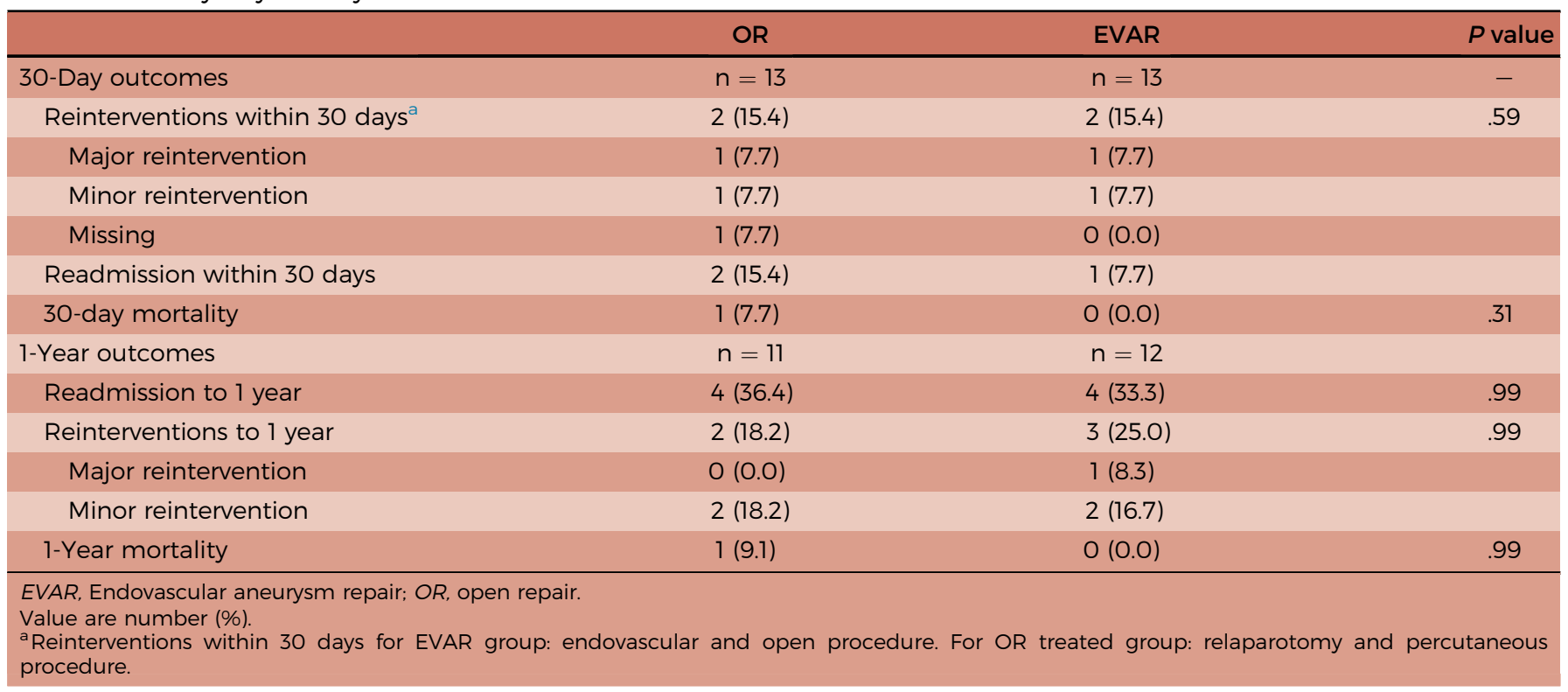

result, we could not analyze all determinants that we aimed for. Moreover, owing to privacy regulations, researchers were not allowed to review patient charts or monitor the data personally. Although data fidelity was confirmed by every vascular surgeon, collecting the data in such retrospective manner could limit the validity of our results. Identification of MAAA cases was also difficult, because some cases were not registered as infectious but rather as inflammatory or unknown.

Finally, the current number of patients is too low to make a reliable comparison of the outcomes of OR and EVAR and to correct for relevant confounders such as patient comorbidity. Moreover, it was highly impractical to include data from before 2016 because the pathogenesis of the aneurysms was not registered back then. Data from 2017, 2018, and 2019 have not been made available yet and therefore could also not be included in this study. Given these limitations, we consider our current study to be exploratory and a starting point for largescale prospective studies.

\section{CONCLUSIONS}

This is the first observational study to provide an overview regarding MAAA treatment in current vascular surgical practice. It shows that MAAA is a rare but challenging disease, with a large heterogeneity in patient characteristics and management. Our study showed acceptable clinical outcomes with OR and EVAR after 1 year of follow-up. Depending on the clinical course, EVAR may be considered in the management of this disease. Future directions should focus on the long term follow-up of EVAR as potential curative treatment, diagnostic criteria for MAAA, and centralization.

\section{DATA SHARING STATEMENT}

Individual participant data that underlie the results reported in this article are available from the corresponding author following publication on reasonable request, after de-identification (text, tables and figures).

\section{AUTHOR CONTRIBUTIONS}

Conception and design: QD, RSVE, JW, HV

Analysis and interpretation: QD, HV

Data collection: QD, RSVE, JW, HV

Writing the article: QD

Critical revision of the article: QD, RSVE, JW, HV

Final approval of the article: QD, RSVE, JW, HV

Statistical analysis: QD, HV

Obtained funding: Not applicable

Overall responsibility:HV

\section{REFERENCES}

1. Osler W. The Gulstonian Lectures, on malignant endocarditis. Br Med J 1885;1:577-9.

2. Kim YW. Infected aneurysm: current management. Ann Vasc Dis 2010;3:7-15.

3. Luo CY, Ko WC, Kan CD, Lin PY, Yang YJ. In situ reconstruction of septic aortic pseudoaneurysm due to Salmonella or Streptococcus microbial aortitis: long-term follow-up. J Vasc Surg 2003:38:975-82.

4. Hsu RB, Chen RJ, Wang SS, Chu SH. Infected aortic aneurysms: clinical outcome and risk factor analysis. J Vasc Surg 2004:40:30-5

5. Woon CY, Sebastian MG, Tay KH, Tan SG. Extra-anatomic revascularization and aortic exclusion for mycotic aneurysms of the infrarenal aorta and iliac arteries in an Asian population. Am J Surg 2008;195:66-72.

6. Muller BT, Wegener OR, Grabitz K, Pillny M, Thomas L, Sandmann W. Mycotic aneurysms of the thoracic and abdominal aorta and iliac arteries: experience with 
anatomic and extra-anatomic repair in 33 cases. J Vasc Surg 2001;33:106-13.

7. Fillmore AJ, Valentine RJ. Surgical mortality in patients with infected aortic aneurysms. J Am Coll Surg 2003;196:435-41.

8. AbdelAzim TA. Infected aortic aneurysms. Acta Chir Belg 2005;105:482-6.

9. Sorelius K, Mani K, Bjorck M, Nyman R, Wanhainen A. Endovascular repair of mycotic aortic aneurysms. J Vasc Surg 2009;50:269-74.

10. Kan CD, Lee HL, Luo CY, Yang YJ. The efficacy of aortic stent grafts in the management of mycotic abdominal aortic aneurysm-institute case management with systemic literature comparison. Ann Vasc Surg 2010;24:433-40.

11. Hsu RB, Chang $\mathrm{Cl}$, Chan $\mathrm{CY}, \mathrm{Wu} \mathrm{IH}$. Infected aneurysms of the suprarenal abdominal aorta. J Vasc Surg 2011;54:972-8.

12. Kan CD, Yen HT, Kan CB, Yang YJ. The feasibility of endovascular aortic repair strategy in treating infected aortic aneurysms. J Vasc Surg 2012;55:55-60.

13. Ishizaka N, Sohmiya K, Miyamura M, Umeda T, Tsuji M, Katsumata $T$, et al. Infected aortic aneurysm and inflammatory aortic aneurysm-in search of an optimal differential diagnosis. J Cardiol 2012;59:123-31.

14. Semba CP, Sakai T, Slonim SM, Razavi MK, Kee ST, Jorgensen $\mathrm{MJ}$, et al. Mycotic aneurysms of the thoracic aorta: repair with use of endovascular stent-grafts. J Vasc Interv Radiol 1998;9:33-40.

15. Sorelius K, Mani K, Bjorck M, Sedivy P, Wahlgren CM, Taylor P, et al. Endovascular treatment of mycotic aortic aneurysms: a European multicenter study. Circulation 2014:130:2136-42.

16. Kan CD, Lee HL, Yang YJ. Outcome after endovascular stent graft treatment for mycotic aortic aneurysm: a systematic review. J Vasc Surg 2007:46:906-12.

17. Dutch Institute for Clinical Auditing (DICA), About DICA. Available at: https://dica.nl/dica/over-dica. Accessed April 1, 2019.

18. PLoS Med Editors. Observational studies: getting clear about transparency. PLoS Med 2014;11:e1001711.

19. Sorelius K, Wanhainen A, Furebring M, Bjorck M, Gillgren P, Mani K, et al. Nationwide study of the treatment of mycotic abdominal aortic aneurysms comparing open and endovascular repair. Circulation 2016;134:1822-32.

20. Sedivy P, Spacek M, El Samman K, Belohlavek O, Mach T, Jindrak $V$, et al. Endovascular treatment of infected aortic aneurysms. Eur J Vasc Endovasc Surg 2012;44:385-94.

21. Jia X, Dong YF, Liu XP, Xiong J, Zhang HP, Guo W. Open and endovascular repair of primary mycotic aortic aneurysms: a 10year single-center experience. J Endovasc Ther 2013;20:305-10.

22. Sorelius K, di Summa PG. On the diagnosis of mycotic aortic aneurysms. Clin Med Insights Cardiol 2018;12. 1179546818759678.

23. Oderich GS, Panneton JM, Bower TC, Cherry $\mathrm{KJ} J \mathrm{~J}$, Rowland CM, Noel AA, et al. Infected aortic aneurysms: aggressive presentation, complicated early outcome, but durable results. J Vasc Surg 2001;34:900-8.

24. Brown SL, Busuttil RW, Baker JD, Machleder HI, Moore WS Barker WF. Bacteriologic and surgical determinants of survival in patients with mycotic aneurysms. J Vasc Surg 1984;1:541-7.

25. Hsu RB, Tsay YG, Wang SS, Chu SH. Surgical treatment for primary infected aneurysm of the descending thoracic aorta, abdominal aorta, and iliac arteries. J Vasc Surg 2002;36:746-50.

26. Uchida N, Katayama A, Tamura K, Miwa S, Masatsugu K, Sueda T. In situ replacement for mycotic aneurysms on the thoracic and abdominal aorta using rifampicin-bonded grafting and omental pedicle grafting. Ann Thorac Surg 2012;93:438-42.
27. Zettervall SL, Schermerhorn ML, Soden PA, McCallum JC Shean KE, Deery SE, et al. The effect of surgeon and hospital volume on mortality after open and endovascular repair of abdominal aortic aneurysms. J Vasc Surg 2017;65: 626-34.

28. Dimick JB, Pronovost PJ, Cowan JA, Ailawadi C Upchurch GR Jr. The volume-outcome effect for abdominal aortic surgery: differences in case-mix or complications? Arch Surg 2002;137:828-32.

29. Holt PJ, Poloniecki JD, Gerrard D, Loftus IM, Thompson MM Meta-analysis and systematic review of the relationship between volume and outcome in abdominal aortic aneurysm surgery. Br J Surg 2007:94:395-403.

30. Gazoni LM, Speir AM, Kron IL, Fonner E, Crosby IK. Elective thoracic aortic aneurysm surgery: better outcomes from high-volume centers. J Am Coll Surg 2010;210:855-9, 859-60.

31. Phillips P, Poku E, Essat M, Woods HB, Goka EA, Kaltenthaler EC, et al. Procedure volume and the association with short-term mortality following abdominal aortic aneurysm repair in European populations: a systematic review. Eur J Vasc Endovasc Surg 2017;53:77-88.

Submitted May 26, 2019; accepted Sep 29, 2019.

Additional material for this article may be found online at www.jvascsurg.org.

\section{APPENDIX.}

Collaborators of Dutch Society of Vascular Surgery, Steering Committee of the Dutch Surgical Aneurysm Audit and Dutch Institute for Clinical Auditing: Van den Akker LH, Van den Akker PJ, Akkersdijk GJ, Akkersdijk GP, Akkersdijk WL, van Andringa de Kempenaer MG, Arts CH, Avontuur JA, Baal JG, Bakker OJ, Balm R, Barendregt $\mathrm{WB}$, Bender $\mathrm{MH}$, Bendermacher $\mathrm{BL}$, van den Berg M, Berger P, Beuk RJ, Blankensteijn JD, Bleker RJ, Bockel JH, Bodegom ME, Bogt KE, Boll AP, Booster $\mathrm{MH}$, Borger van der Burg BL, de Borst GJ, Bos- van Rossum WT, Bosma J, Botman JM, Bouwman LH, Breek JC, Brehm V, Brinckman MJ, van den Broek TH, Brom HL, de Bruijn MT, de Bruin JL, Brummel P, van Brussel JP, Buijk SE, Buimer MG, Burger DH, Buscher HC, den Butter G, Cancrinus E, Castenmiller PH, Cazander C, Coveliers HM, Cuypers PH, Daemen JH, Dawson I, Derom AF, Dijkema AR, Diks J, Dinkelman MK, Dirven M, Dolmans $D E$, van Doorn RC, van Dortmont LM, van der Eb MM, Eefting D, van Eijck GJ, Elshof JW, Elsman BH, van der Elst $A$, van Engeland $\mathrm{MI}$, van Eps RG, Faber $\mathrm{MJ}$, de Fijter WM, Fioole B, Fritschy WM, Geelkerken RH, van Gent WB, Glade GJ, Govaert B, Groenendijk RP, de Groot HG, van den Haak RF, de Haan EF, Hajer GF, Hamming $J F$, van Hattum ES, Hazenberg CE, Hedeman Joosten PP, Helleman JN, van der Hem LG, Hendriks JM, van Herwaarden JA, Heyligers JM, Hinnen JW, Hissink RJ, Ho GH, den Hoed PT, Hoedt MT, van Hoek F, Hoencamp R, Hoffmann WH, Hoksbergen AW, Hollander EJ, Huisman LC, Hulsebos RG. Huntjens KM, Idu MM, Jacobs MJ, van 
der Jagt MF, Jansbeken JR, Janssen RJ, Jiang $\mathrm{HH}$, de Jong SC, Jongkind V, Kapma MR, Keller BP, Khodadade Jahrome A, Kievit JK, Klemm PL, Klinkert P, Knippenberg B, Koedam NA, Koelemaij MJ, Kolkert JL, Koning $\mathrm{GG}$, Koning $\mathrm{OH}$, Krasznai AG, Krol RM, Kropman RH, Kruse RR, van der Laan L, van der Laan MJ, van Laanen JH, Lardenoye JH, Lawson JA, Legemate DA, Leijdekkers VJ, Lemson MS, Lensvelt MM, Lijkwan MA, Lind RC, van der Linden FT, Liqui Lung PF, Loos MJ, Loubert MC, Mahmoud DE, Manshanden CG, Mattens EC, Meerwaldt R, Mees BM, Metz R, Minnee RC, de Mol van Otterloo JC, Moll FL, Montauban van Swijndregt YC, Morak MJ, van de Mortel RH, Mulder W, Nagesser SK, Naves CC, Nederhoed JH, Nevenzel-Putters AM, de Nie AJ, Nieuwenhuis $\mathrm{DH}$, Nieuwenhuizen $\mathrm{J}$, van Nieuwenhuizen RC, Nio D, Oomen AP, Oranen BI, Oskam J, Palamba HW, Peppelenbosch AG, van Petersen AS, Peterson TF, Petri BJ, Pierie ME, Ploeg AJ, Pol RA, Ponfoort ED, Poyck PP, Prent A, ten Raa S, Raymakers JT, Reichart M, Reichmann BL, Reijnen MM, Rijbroek A, van Rijn MJ, de Roo RA, Rouwet EV, Rupert CG, Saleem BR, van Sambeek MR, Samyn MG, van 't Sant HP, van Schaik J, van Schaik
PM, Scharn DM, Scheltinga MR, Schepers A, Schlejen PM, Schlosser FJ, Schol FP, Schouten O, Schreinemacher $\mathrm{MH}$, Schreve MA, Schurink $\mathrm{CW}$, Sikkink $\mathrm{CJ}$, te Slaa A, Smeets HJ, Smeets L, de Smet AA, de Smit P, Smit PC, Smits TM, Snoeijs MG, Sondakh AO, van der Steenhoven TJ, van Sterkenburg SM, Stigter DA, Stigter $H$, Strating RP, Stultiëns GN, Sybrandy JE, Teijink JA, Telgenkamp BJ, Testroote MJ, The RM, Thijsse WJ, Tielliu IF, van Tongeren RB, Toorop RJ, Tordoir JH, Tournoij E, Truijers M, Türkcan K, Tutein Nolthenius RP, Ünlü Ç, Vafi AA, Vahl AC, Veen EJ, Veger HT, Veldman MG, Verhagen $\mathrm{HJ}$, Verhoeven BA, Vermeulen CF, Vermeulen EG, Vierhout BP, Visser MJ, van der Vliet JA, Vlijmen van Keulen $\mathrm{CJ}$, Voesten $\mathrm{HG}$, Voorhoeve R, Vos AW, de Vos B, Vos CA, Vriens BH, Vriens PW, de Vries AC, de Vries JP, de Vries M, van der Waal C, Waasdorp EJ, Wallis de Vries BM, van Walraven LA, van Wanroij JL, Warlé MC, van Weel V, van Well AM, Welten GM, Welten RJ, Wever $\mathrm{JJ}$, Wiersema AM, Wikkeling OR, Willaert WI, Wille J, Willems MC, Willigendael EM, Wisselink W, Witte ME, Wittens $\mathrm{CH}$, Wolf-de Jonge IC, Yazar $\mathrm{O}$, Zeebregts $\mathrm{CJ}$, and van Zeeland $\mathrm{ML}$. 